\title{
Reconstrução Teórica do Cuidado para as Práticas de Saúde: Um Olhar a Partir da Produção de Alunos de Curso de Especialização a Distância*
}

PALAVRAS-CHAVE

- Assistência à saúde;

- Educação superior;

- Serviços de saúde;

- Educação Médica.

KEY WORDS

- Healthcare;

- Higher education;

- Health services;

- Medical Education.

Recebido em:19/07/2007

Reencaminhado em: 26/10/2007

Aprovado em: 26/10/2007

$291 \frac{\text { REVISTA BRASILEII }}{32(3): 291-300 ; 2008}$

\section{Theoretical Reconstruction of Caregiving for the Healthcare Practice: Observations Based on the Production of Students in a Distance- learning Specialization Program}

Maria de Lourdes da Silva Marques Ferreiral Rosângela Minardi Mitre Cotta ${ }^{I I}$ Marilda Siriani de Oliveira ${ }^{I I I}$

\section{RESUMO}

Este estudo analisa a produção coletiva realizada por um grupo de tutores do curso de especialização a distância "Ativação de processos de mudança na formação superior de profissionais de saúde", sobre cuidado em saúde. A questão debatida foi: como os diferentes sentidos do cuidado devem orientar as práticas do cuidado à saúde num contexto de articulação ensino-serviço-comunidade? Utilizou-se para análise da produção a técnica de análise de conteúdo. As categorias sobre cuidado em saúde foram: ontológica, crítica, reconstrutiva e genealógica. O enfoque central foi uma abordagem do cuidado que extrapola o ato técnico, por meio de pactos, compartilhamento de poderes, parcerias e utilização do método da roda. A formação dos ativadores objetivou contribuir para uma assistência qualificada e comprometida com as necessidades dos usuários. Destaca-se a importância da articulação da academia, enquanto órgão formador, do serviço, como exercício da prática e da comunidade que receberá o cuidado, sob uma nova ótica - centrada no usuário, ou seja, enquanto sujeito participativo e protagonista do processo de produção do cuidado.

ABSTRACT
The present study analyzes the collective production of a group of tutors of the long-distance speciali-
zation course "Activation of change processes in higher education of health professionals" about caregi-
ving. The question in debate was: how should the different meanings of caregiving guide the healthcare
practices in the context of the articulation teaching-service-community? The production was analyzed
following the content analysis technique. The following categories about health care were: ontological,
critical, reconstructive and genealogical. The central focus was an approach to care that extrapolated
the technical act, through pacts, sharing of power, partnerships and utilization of the "wheel method".
The preparation of activators was aimed at contributing to qualified care committed to the needs of the
users. The study highlights the importance of articulation of the university as teaching institution, of
service in the sense of professional practice, and of the community that will receive the care from a new
user-centered perspective, as both subject and protagonist in the process of care production.

"Trabalho realizado durante o curso de especialização semi-presencial "Ativação de processos de mudança na formação superior de profissionais de saúde". ${ }^{I}$ Faculdade de Medicina de Botucatu, São Paulo, Brasil.

"Iniversidade Federal de Viçosa, Minas Gerais, Brasil.

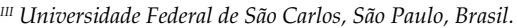




\section{INTRODUÇÃO}

As constantes mudanças que consubstanciam o mundo atual, trazendo repercussões no âmbito da política, da economia e da cultura, exigem respostas no campo do trabalho e da formação para o trabalho, que, para as profissões da área da saúde, vão além da capacidade técnica especializada ${ }^{1}$.

Assim, o novo modelo almejado pelas instituições de saúde no âmbito do Sistema Único de Saúde (SUS) busca profissionais com perfis diferenciados daquele encontrado no ensino tradicional, que, por conseqüência, exige um novo modelo de ensino.

A formação dos profissionais da área da saúde numa perspectiva crítico-reflexiva para atender às reais demandas contemporâneas e da população a ser assistida tem mobilizado discussões entre docentes na atualidade. Neste sentido, a articulação do saber com o fazer vem ganhando espaço de reflexão entre os profissionais da academia e profissionais do serviço, para o estabelecimento de vínculo e alianças para uma assistência qualificada.

Neste contexto de transformações no cenário da educação, a educação a distância tem ganhado espaço, com tecnologia cada vez mais avançada, propiciando aos profissionais com atividades em tempo integral a realização de cursos de aperfeiçoamento e atualização da teoria e prática.

$\mathrm{O}$ aprendizado on line é uma das expansões mais rápidas da educação no ensino superior nos dias atuais. Os cursos on line são oferecidos cada vez mais freqüentemente na atualidade, destacando-se como ponto importante em ambientes virtuais o aprendizado colaborativo ${ }^{2}$.

A educação a distância surgiu a princípio como uma proposta de solução para o descompasso entre a oferta e a demanda presentes na sociedade no sistema educacional brasileiro, que elitiza o mundo do saber com exclusão de grande contingente da população ${ }^{3}$.

O conhecimento no aprendizado on line é construído conjuntamente, e todos podem participar e intervir no processo por meio da criação e reconstrução das mensagens (co-autoria), com opção para selecionar, combinar e permutar estas informações, além de produzir outras narrativas possíveis na sua potencialidade ${ }^{4}$

A participação em um curso oferecido a distância com oficinas presenciais estratégicas possibilitou o encontro de uma equipe multiprofissional que discutia temáticas da saúde por intermédio de três eixos temáticos: político-gerencial, educacional e cuidado à saúde. Desta perspectiva, este trabalho tem por objetivo central analisar o conteúdo das descrições de um grupo de tutores sobre o eixo temático do cuidado à saúde, no fórum do curso de especialização a distância "Ativação de processos de mudança na formação superior de profissionais de saúde", promovido pelo Ministério da Saúde (MS), Fundação Oswaldo Cruz (Fiocruz), Escola Nacional de Saúde Pública (ENSP - EAD) e Rede Unida.

Este estudo busca realizar ainda, com a análise, uma desconstrução teórica com vistas a contribuir para a reconstrução das práticas de saúde relacionadas ao cuidado a partir de uma prática de ensino a distância.

\section{SUJEITOS E MÉTODOS}

O acervo analisado é constituído por 315 participações, formado por nove profissionais de saúde que realizam o curso como tutores vinculados a academias e serviços, coordenados por um orientador de aprendizagem que atuou como facilitador.

Desde o marco teórico da metodologia ativa, o orientador de aprendizagem tem o propósito de promover o autodescobrimento (insight - o dar-se conta). As intervenções do orientador de aprendizagem tentam gerar uma reflexão por parte dos participantes, assim como formular perguntas que deixem em descoberto certos aspectos da problemática. O esforço se concentra em lograr que os próprios integrantes do grupo, por meio da visualização dos "conflitos", possam interatuar de forma adequada e se instrumentalizem para abordar adequadamente as necessárias transformações em suas aldeias, como parte de suas reflexões, críticas e propostas de mudanças ${ }^{5}$.

O trabalho se desenvolveu no fórum intitulado "Processamento da situação da prática", cujo objetivo é a discussão da seguinte questão norteadora: "Quais e como os sentidos do cuidado devem orientar as práticas do cuidado à saúde num contexto de articulação ensino-serviço-comunidade"?

O fórum foi uma das ferramentas utilizadas a distância, ocorrendo sempre após uma oficina presencial e sendo aberto pelo orientador de aprendizagem, com temáticas relacionadas aos eixos do curso: Educação, Político-Gerencial, Cuidado à Saúde. Uma situação-problema foi previamente elegida pelo grupo após uma busca ativa em estudos, artigos e livros, de forma individualizada num primeiro momento. Posteriormente, a situação foi problematizada pelo grupo, com identificação de lacunas do conhecimento que geram questões de aprendizagem por meio da elaboração de uma síntese provisória. Tais questões foram trabalhadas no fórum, on line, no subseqüente momento a distância.

As mensagens aqui analisadas correspondem à produção coletiva do grupo no período de 28 de agosto a 12 de outubro de 2005. 


\section{Análise das mensagens}

Utilizou-se a técnica de análise de conteúdo ${ }^{6}$, que consiste em depurar descrições de conteúdo muito aproximadas, subjetivas, e pôr em evidência, com objetividade, a natureza e as forças relativas dos estímulos a que o sujeito é submetido. Esta técnica utiliza procedimentos do conteúdo das mensagens, indicadores que permitem realizar inferências. A análise do conteúdo desdobra-se em três etapas:

- Pré-análise - é a fase de escolha dos documentos a serem analisados e a organização propriamente dita. Nesta fase realizou-se a leitura das participações sobre o cuidado no fórum pelos profissionais do grupo, sendo essas participações os documentos que tivemos em mãos para análise;

- Exploração do material - nesse segundo momento classificou-se o material em sistemas de unidades de significação, reunindo-os de acordo com seu significado segundo categorias previamente estabelecidas;

- Tratamento dos resultados obtidos e interpretação são atribuídas significações aos resultados brutos por meio de recortes e estabelecimento das unidades de significação e após a interpretação destes resultados.

A opção pela análise temática pareceu-nos pertinente, visto que a mesma se presta a estudar tendências, valores, crenças e conteúdos em destaque sobre temas específicos neste estudo sobre o cuidado com a participação de profissionais de diferentes formações acadêmicas.

\section{RESULTADOS E DISCUSSÃO}

\section{Caracterização da população}

O grupo participante é formado por uma equipe multiprofissional constituída por quatro enfermeiras, três médicos — um deles do sexo masculino - , uma terapeuta ocupacional e uma psicóloga. Todos os profissionais estão na docência em instituições públicas e privadas e carregam na bagagem um ideal de mudança no ensino superior. Daí a iniciativa de participar do curso de especialização em ativação de processos de mudança na formação superior de profissionais de saúde, primeiramente como especializandos e posteriormente como tutores na formação de profissionais da área da saúde.

As descrições obtidas no fórum estão respaldadas em literatura científica pertinente à temática e inerente à bagagem de conhecimento dos profissionais de saúde que dele participaram. Assim, nos resultados, os autores referendados por meio dos depoimentos dos participantes no fórum são utilizados como suporte teórico das discussões. Os participantes foram identificados com a sigla P seguida do número de entrada no fórum, portanto de P1 até P9.
As categorias preestabelecidas foram elaboradas utilizando-se o referencial de Ayres $^{7}$ e a partir delas as unidades de significação.

\section{DISCURSO DO CUIDADO COMO CATEGORIA ONTOLÓGICA}

Ontologia é uma especificação de uma conceituação, isto é, uma descrição de conceitos e relações existentes em um domínio de interesse. Basicamente, uma ontologia consiste nesses conceitos e relações, e suas definições, propriedades e restrições são descritas em forma de axiomas.

A categorização ontológica permite aos profissionais explicar o seu entendimento sobre o cuidado, o que os faz refletir e melhorar sua compreensão sobre esse tema. E faz com que sejam explicitadas as diferenças no entendimento da exploração do cuidado à saúde, buscando-se um consenso sobre seu significado e sua importância ${ }^{8}$.

Normalmente quando se fala em cuidado à saúde, há muitas definições. Uma delas é a significação do senso comum, que é o conjunto de procedimentos tecnicamente orientados para o bom êxito de certo tratamento ${ }^{7}$. No entanto, o cuidado que queremos aqui analisar extrapola o conjunto de recursos e medidas terapêuticas e procedimentos auxiliares, em que buscamos uma compreensão filosófica e uma atitude prática frente ao sentido que as ações de saúde adquirem nas múltiplas situações em que o cuidado acontece.

\section{Unidades de significação}

a) Conceituação teórica

O cuidado é atenção, cautela, desvelo, zelo, entendido cuidado como troca, doação. Não dá para pensar em cuidado como uma ação pontual, como cuidado estritamente técnico desconectado de uma realidade individual e social (P2). O conceito é mais que um ato,é uma atitude, representando uma atitude de ocupação, preocupação, responsabilização e de envolvimento afetivo com o outro (P4).

Nessas definições que extrapolam a técnica, refletimos o cuidado enquanto prática associada à condição do humano e, neste sentido, "o ser humano é um ser de cuidado, mais ainda, sua essência se encontra no cuidado. Colocar cuidado em tudo o que projeta - eis a característica do ser humano" ${ }^{\prime \prime}$.

O processo do cuidado é múltiplo e complexo, mas não é impossível. Se o cuidado se dá nas relações, é necessário pensarmos sobre as dimensões do cuidado seja 
do ponto de vista conceitual para atribuir significações e significados das próprias palavras para sair do conceito do cuidado para os modelos das práticas de saúde, cujo cuidado é o cerne principal da razão da existência dos serviços de saúde (P7).

As práticas assistenciais são reconhecidas como espaços relacionais capazes de criar e recriar práticas que extrapolam o plano tecnocientífico. Apóia-se na tecnologia, mas não se subordina a ela, subverte-a. "Estabelece-se a partir e em torno dos universais que ela carreia, mas cobra-lhe os limites"10.

Entende-se o cuidado como uma relação amorosa com a realidade, no investimento de zelo, desvelo, solicitude, atenção e proteção para com aquilo que tem valor e interesse para nós, constituindo-se assim em uma plataforma real que possibilita as demais dimensões do humano emergir (P6). Cuidar é mais que caminhar juntos, é solidarizar-se com o outro no caminho ou na construção do caminhar e estar aberto para receber outros durante a caminhada (P5).

O cuidado pressupõe uma relação, e essa relação não deve ser de domínio sobre o outro, mas de con-vivência. O cuidado se dá na "inter-ação e comunhão"

Cuidar é saber ouvir e falar com atenção e respeito à vida humana, não só no sentido do atendimento ao usuário, mas também na participação do planejamento e avaliação do serviço onde se trabalha (P4). Na dimensão do cuidado, recorre-se ainda à definição de recurso terapêutico como sendo parte essencial da clínica que estuda e põe em prática os meios adequados para curar, reabilitar, aliviar o sofrimento e prevenir possíveis danos em pessoas vulneráveis ou doentes, que vai além de uma preocupação humanizadora, almejando uma técnica que qualifica o trabalho em saúde (P3).

Por meio das práticas da saúde nem sempre é possível curar ou resolver uma necessidade apresentada, mas é sempre possível cuidar, escutar e contribuir para amenizar o sofrimento do outro. Junto com alguém que sofre, sofrem os que o amam, o sofrimento é então compartilhado, ainda que não dividido. Por isso, é patente a necessidade de trabalhadores sensíveis, com uma nova ética na saúde na atividade do cuidar ${ }^{11}$.

Pode-se constatar que a conceituação dos diferentes profissionais de saúde vai além da definição restrita do cuidado enquanto simplesmente técnica e procedimentos, atingindo uma dimensão maior, que tem como aporte a complexidade do processo de cuidar, incluindo respeito à vida humana, escuta, responsabilidade e considerando aspectos da vida social do indivíduo.

\section{b) Cuidado associado à dimensão do acolhimento $e$ organização do serviço de saúde centrado no usuário}

Os pacientes precisam ser acolhidos no momento em que procuram assistência, pressupondo, assim, a disposição, organização e preparação da equipe para receber, em vários momentos e em diferentes horários, uma diversidade de demandas, avaliando os riscos implicados e assegurando o seu atendimento e o trabalho em equipe (P1). Na relação de acolhimento e poder, as relações interpessoais podem estabelecer posições determinando lugares onde se dão as relações de subjetividade na dimensão do poder (P9). É preciso rever se, no processo de escutar e acolher, está acontecendo uma relação de horizontalidade, com estabelecimento de diálogo com a comunidade para saber que tipo de escuta e de acolhimento esta população deseja (P2). No ato de cuidar e ser cuidado faz-se necessário ter sensibilidade para saber entender o discurso e o tempo do outro (P3)

Neste processo de cuidar e ser cuidado, a comunicação se apresenta como um elo entre o cliente e o enfermeiro, um elemento indispensável à qualidade das relações, à identificação do processo saúde-doença e à realização do cuidado, pois determina uma prática humanizada, na qual ocorre uma troca de mensagens compartilhadas, enviadas e recebidas. Para que a comunicação seja efetiva, o enfermeiro precisa compreender o ser humano como um ser ativo e o cuidado como finalidade nas mais variadas situações de vida ${ }^{12}$.

O acolhimento pressupõe que o serviço de saúde seja organizado de forma usuário-centrado para garantir a acessibilidade, trabalho em equipe multiprofissional e qualificação da relação profissional-usuário (P8).

Recentemente, promissoras perspectivas têm se aberto na expectativa de que as decisões sobre o tratamento e o cuidado possam ser efetivamente partilhadas entre usuários dos serviços e profissionais de saúde. Esta possibilidade de abrir um diálogo e partilhar juízos e decisões, enfim, abrir uma interação de outra modalidade, é um dos desafios colocados aos profissionais de saúde, especialmente ao médico, frente à "crise de 
confiança" que se estabeleceu em relação à medicina tecnológica, com fortes repercussões na relação médico-paciente ${ }^{13}$.

\section{c) Cuidado como modos de ser do humano e em especial do cuidador}

No sentido de iluminar desafios conceituais e práticos para a humanização das práticas de saúde, o cuidado passa pelas relações com os modos de ser do humano desde uma perspectiva reflexiva que se estrutura em torno da noção de cuidado como uma série de princípios teóricos e práticos (P4). A prática do cuidado passa pela conceituação de quem cuida, cuida de alguém, e o maior objetivo é desenvolver para esse alguém a condição e o direito de sua autonomia; e a equipe deve estar preparada para saber cuidar suficientemente de seus pacientes-usuários (P9).

O cuidado somente surge quando a existência de alguém tem importância para outro alguém. Passa-se, então, a dedicarse a ele, dispondo-se a participar de seu destino, de suas buscas, de seus sofrimentos e de suas conquistas, enfim, de sua vida'.

\section{d) Politicidade do cuidado}

A relação de poder, democracia, grupo coletivo guarda estreita relação com o acolhimento no cuidado. Para que este poder seja democratizado e a população passe da situação de figurante para protagonista, necessitamos reorganizar o processo de trabalho, aprendendo a escutar e acolher (P1). Construir formas de escuta, de cuidado, de acolhida só é possível em contextos democráticos, e assim temos que pensar, inventar, criar modos de construir democracia e, mais ainda, modos de construir pessoas potentes para sustentá-la (P7).

A partir da concepção ampla do cuidado há a caracterização de integração, confronto e ruptura presentes nas dinâmicas vivas que se estabelecem entre os seres humanos em geral e em particular entre os humanos. Assim, significam entender o cuidar no âmbito da centralidade política que define onde a proteção zelosa que se delineia pode constituir tanto um mecanismo de dominação, quanto um instrumento de autonomia dos sujeitos, sejam estes profissionais, técnicos, gestores ou usuários. Nesta direção, entende-se cuidado como reconstrução da ajuda para o fortalecimento da autonomia do outro, calcada em relações de poder que podem tanto oprimir quanto emancipar ${ }^{14}$.

\section{e) $O$ "cuidado" como síntese de muitos cuidados}

O processo do cuidar não é isolado em especialidades ou formação acadêmica, a assistência multiprofissional permite vislumbrar caminhos diversos no cuidado (P2). O cuidado multiprofissional possibilita consolidar planos coletivos e individuais, atendendo no sentido de expectativa e esperança (P4).

O trabalho em equipe requer humildade, solidariedade e tolerância, ou seja, sem alteridade não existe cuidado, crescimento e nem alegria (P7). A assistência multiprofissional aproxima os sujeitos, pelo humanismo das relações e pela ampliação da consciência, para operacionalizar ações de cuidado de cunho ético, respeitoso e compromissado, e a criação do vínculo, que nada mais é do que a interação, relação e inter-relação de pessoas (P5).

O cuidado, nas organizações de saúde em geral, e no hospital em particular, é, por sua natureza, necessariamente multidisciplinar, isto é, depende da conjugação do trabalho de vários profissionais. O cuidado, de forma idealizada, recebido/vivido pelo paciente é um somatório de muitos pequenos cuidados parciais que vão se complementando, de maneira mais ou menos consciente e negociada, entre os vários cuidadores que circulam e produzem a vida do hospital ${ }^{15}$.

\section{DISCURSO DO CUIDADO COMO CATEGORIA GENEALÓGICA}

Esta categoria reflete muito o cuidado de si, que adquiriu um alcance bem geral, porque o cuidado de si é um imperativo que circula numerosas doutrinas diferentes, na atitude, maneira de se comportar, formas de viver, procedimentos executados, práticas que eram refletidas, desenvolvidas, aperfeiçoadas e ensinadas, constituindo uma prática social, dando lugar a relações interindividuais, trocas e comunicações; ele proporciona, enfim, certo modo de conhecimento e a elaboração de um saber ${ }^{16}$.

\section{Unidades de significação}

\section{a) $\mathrm{O}$ cuidado de si}

Esta unidade de significado é única para a categoria genealógica, pois utilizamos como referencial para a construção e discussão os ensinamentos de Foucault ${ }^{16}$.

Quando refletimos sobre o cuidado de si e do outro, pensamos o quanto nós, cuidadores e usuários do cuidado, percebemos a capacidade de nos olhar e perceber sem a participação da tecnologia, que anda cada vez mais avançada (P2). 
A busca de sentido e de significado da vida é uma das necessidades fundamentais do ser humano, como também do profissional de saúde, docente, discente e usuário dos serviços de saúde (P3).

O cuidado de si constitui, simultaneamente, um atributo e uma necessidade universal dos seres humanos, regidos por princípios de aplicação geral, embora orientados para uma prática de escopo e responsabilidades absolutamente individuais. Não mais um prazer ou uma prerrogativa, não se cuidar é sucumbir, e para não sucumbir é preciso conhecer a verdade de que a razão a todos pode dar acesso ${ }^{16}$.

O sentimento de cuidar de si é despertado no indivíduo quando descobre que está em estado de necessidade. O ser humano é o único da natureza que foi encarregado do cuidado de si próprio, diferindo desta maneira dos animais. Na arte da existência, encontra-se o princípio segundo o qual é preciso ter cuidados consigo ${ }^{16}$.

O cuidado objetiva independência do cuidador e de quem é cuidado, seja ele paciente, população, equipe ou aluno (P7).

Sabe-se que o cuidado tem por objetivo a autonomia do ser humano, do cuidador, do que é cuidado, e essa autonomia sempre começa com o reconhecimento do agente do cuidado para com ele mesmo - o cuidado de $\mathrm{si}^{17}$ :

A importância de mim mesmo na relação com o outro só se alcança quando se procura conhecer seu próprio ser (P4).

Quem cuida é cuidado ao cuidar, tendo um significado nesta relação do eu cuidador e cuidado com o outro da "con-vivência", porque cuidar e ser cuidado são elementos essenciais da prática na vida (P8). O cuidado de si também passa pela limitação de quem cuida e está no seu limite e necessita ser cuidado (P1).

Quem cuida de modo adequado de si mesmo encontra-se em condições de se relacionar, de se conduzir adequadamente na relação com os demais ${ }^{17}$.

A compreensão do cuidado demonstrada pelos profissionais especializandos se relaciona com a sua formação acadêmica, associada à prática assistencial. Tendo como pressuposto que, para cuidar do outro, o aluno necessita aprender a cuidar de si mesmo e a ser cuidado, acredita-se que é importante compreender o aluno como alguém que se encontra em processo de desenvolvimento e que precisa ser auxiliado nesse período de formação, para que no futuro esteja mais capacitado a cuidar de pessoas ${ }^{18}$

Assim, acreditamos que o ensino dos profissionais de saúde extrapola os aspectos técnicos e é preciso rever a metodologia de aprendizagem, considerando o aluno como sujeito ativo neste processo e possibilitando uma formação crítico-reflexiva.

\section{DISCURSO DO CUIDADO COMO CATEGORIA CRÍTICA}

O cuidado como categoria crítica refere-se à questão do cuidado como modo de interação nas e pelas práticas de saúde em seus moldes contemporâneos, restringindo-nos agora às tecnologias já configuradas como campo institucional das práticas de saúde ${ }^{7}$.

\section{Unidades de significação}

\section{a) Questionando a integralidade no cuidado}

A integralidade no cuidado para que este seja realizado considerando o paciente com a doença e não a doença no paciente é um dos princípios do cuidado humanizado.

Daí surge a crítica em relação à atitude médica fragmentária e ao sistema que privilegia a especialização e segmentação; à atitude médica reducionista; e à formação médica de base flexneriana, que reduz o paciente ao aparelho ou sistema biológico que supostamente produz o sofrimento e, portanto, a queixa do paciente.

Não dá para falar em cuidar e em acolhimento sem pensar na integralidade, no como acolher, no como cuidar sem se inter-relacionar, na comunicação, na referência e contra-referência, no ir e vir do usuário. É necessário que o usuário do SUS deixe de ser um verdadeiro andarilho (P4).

A integralidade se forma com o coletivo, com o reconhecimento do gestor da importância da educação permanente na proposta de reformulação da estrutura e processo em tempo e lugar. Seria equivocado esperar um conceito unívoco para integralidade, pois esta perderia a sua totalidade e se incorreria na possibilidade de restringir alguns de seus sentidos ainda inacabados, potenciais vetores de transformação das práticas no Sistema Único de Saúde ${ }^{19}$.

Quando falamos em cuidado, há necessidades a serem atendidas, vinculadas à integralidade e ao respeito pelas necessidades sentidas do outro. Deve-se ter abertura para a expressão de ambos os sentimentos do cuidador e daquele que será cuidado, estabelecendo 
respeito mútuo, amor e paz para extrapolar a tirania dos exames, a excessiva segmentação do paciente em órgãos e funções (P8).

Quando falamos em integralidade, falamos em integralidade da vida, e o ponto importante nesta questão é a tolerância e respeito à diversidade de representações do cuidado para cada um, e para isto é preciso estabelecer um vínculo (P1).

$\mathrm{O}$ vínculo seria um meio para a realização de uma prática clínica de qualidade e integral, partindo da aproximação afetiva entre os sujeitos que cuidam e os sujeitos que são cuidados, e do reconhecimento legítimo do saber biomédico, porém agregado ao saber difundido, e também legítimo, dos ritos e práticas populares ${ }^{20,21}$.

\section{b) Discutindo a multiplicidade das necessidades e a multidisciplinaridade da equipe}

É preciso que o profissional de saúde compreenda o conjunto das necessidades de ações e serviços de saúde que um paciente apresenta para além da atenção individual curativa, incorporação de ações de promoção e prevenção na atenção à saúde e articulação com ações curativas e reabilitadoras (P6).

O cuidado multidisciplinar permite a construção de um processo de trabalho que pode ser realizado de forma cooperativa entre os diversos profissionais envolvidos, com suas formas todas de "ver" o paciente e projetar o que seria bom para ele ${ }^{22}$.

O cuidado em saúde, quando exercido com as devidas características de multiprofissionalismo e interdisciplinaridade, obtém melhores resultados em termos de qualidade técnica e humana do que as formas usuais de organização do cuidado, que estão centradas no monoprofissionalismo do profissional de saúde ou na plenipotência de seus saberes e de suas técnicas ${ }^{22}$.

$\mathrm{Na}$ medicina contemporânea identificam-se importantes avanços e aceleração na ampliação do poder de diagnóstico, na precocidade progressivamente maior da intervenção terapêutica, no aumento da eficácia, eficiência, precisão e segurança dessa intervenção e na melhora do prognóstico e qualidade de vida dos pacientes em uma série de agravos (P2).

É importante atuar no processo de construir uma formação e uma atenção à saúde centradas na pessoa, isto é, no cuidado ao paciente e noensinodoestudante (P3).
Os serviços de saúde que pretendam de fato se responsabilizar pelos problemas da saúde precisam ter por base a ampliação do que se denomina "coeficiente de autonomia" dos sujeitos usuários. A prática em saúde introduz os aspectos singulares do indivíduo, da família e da comunidade na condução terapêutica por meio do compartilhamento de saberes entre trabalhador e usuário como forma de garantir resultados eficientes no processo de cura e/ou no controle das morbimortalidades ${ }^{23}$.

Fica evidente em pesquisas sobre ensino a preocupação em buscar ações mais intensas para a formação de profissionais conscientes de cidadania, independência de pensamento e capacidade crítica. Fala-se muito na formação de cidadãos que saibam ler o mundo em que estão inseridos e que sejam capazes de transformar esse mundo para melhor ${ }^{24}$. No entanto, a perspectiva da "transmissão" e a crença de que basta ter "domínio do conteúdo", infelizmente, predominam nos cursos superiores ainda hoje ${ }^{25}$.

Os alunos especializandos sujeitos deste estudo trazem esse discurso na categoria crítica, reconhecendo a necessidade de mudança no ensino superior para contemplar as facetas da integralidade e multidisciplinaridade no ensino da graduação, a fim de que haja um distanciamento desejável da desfragmentação do conhecimento. Há uma inadequação cada vez mais agravada entre os saberes - separados, fragmentados, compartimentados entre disciplinas - e as realidades ou problemas da realidade global, complexa e multidimensional. O desenvolvimento disciplinar das ciências, apesar de ter trazido as vantagens da divisão do trabalho, gerou a hiperespecialização, impedindo que se veja o global, pois, espedaçando em parcelas o saber e fragmentando os problemas, inibe as possibilidades de reflexão e compreensão do todo ${ }^{26}$.

\section{DISCURSO DO CUIDADO COMO CATEGORIA RECONSTRUTIVA}

Nesta categoria existe uma potencialidade reconciliadora entre as práticas assistenciais e a vida, ou seja, a possibilidade de um diálogo aberto e produtivo entre a tecnociência médica e a construção livre e solidária de uma vida que se quer feliz, a que estamos chamando de cuidado ${ }^{7}$.

\section{Unidades de significação}

a) Reconciliação das práticas assistenciais com diálogo aberto do sujeito assistido

A relação assistência-diálogo pode gerar angústia aos profissionais de saúde, pelo conhecimento da realidade, transformando-a de uma realidade imaginária, 
virtual, possivel, para uma concretude real, que muitas vezes é fator estressante, pela incapacidade de ajuda que vá de encontro a esta relação proposta, devido a uma correlação de forças entre omissão e limitação da atenção ao cuidado prestado (P3).

O cuidado se caracteriza como um encontro, repetido durante espaços de tempo e no qual seres vivos, seres humanos, dentro de uma unidade de saúde ou de um ambiente hospitalar, se defrontam, interagem, se comunicam e se influenciam mutuamente. Isso se caracteriza como um processo, um trajeto, que leva a uma convergência entre o cuidador e o ser cuidado $^{12}$.

Com relação ao cuidado, aspectos importantes são aqueles referentes à exclusão, no sentido da incapacidade de suprir carências humanas básicas, à falta de amor, no sentido da impossibilidade de construir e estabelecer vínculos de afeto com o outro (P9).

Os serviços de saúde assumem a função de acolher, escutar e dar uma resposta positiva aos problemas de saúde da população (P7).

Saber ouvir é muito mais do que escutar e dar a nossa interpretação conforme desejarmos ou baseados em nossas próprias limitações. Saber ouvir é cultivar a difícil arte da empatia. Empatia refere-se à habilidade de se colocar no lugar do outro, prestando atenção no significado do que está sendo dito; na maneira como a mensagem está sendo transmitida; no estado emocional, limites e conhecimentos do transmissor; é olhar para os olhos, é perguntar caso haja dúvidas, é evitar interpretar a partir do que foi dito ${ }^{27}$.

Na relação do cuidado-diálogo humanizado é preciso reorganizar o processo de trabalho a fim de que este desloque seu eixo central do método para uma equipe multiprofissional-equipe de acolhimento e qualificar a relação entre trabalhador-usuário em parâmetros humanitários (P8).

É preciso que o profissional de saúde considere o sujeito, suas escolhas, seu modo de viver e de sentir e descrever o adoecimento que efetivamente farão a diferença na clínica que se opera, independentemente da especialidade que se coloca (P5).

As ações de assistência só têm significado quando o cuidado resulta de um processo interativo, no qual a intencionalidade do agir e o conhecimento que se espera de cada um no processo de cuidar sejam manifestos. Desta forma, estabelecese uma relação pautada no encontro, com uma comunicação efetiva ${ }^{12}$.

Aliada a esta comunicação profissional-paciente está a relação professor-aluno. A formação acadêmica deve privilegiar situações de aprendizagem que promovam atitudes criativas, críticas e transformadoras, para que os alunos possam ser profissionais criativos, críticos e transformadores da realidade onde se encontram seus pacientes ${ }^{28}$.

\section{b) Reconstruindo com o método da roda}

O sugerido método da roda propõe sair do modelo de promoção e prevenção sobre os usuários e não com a participação deles, onde os programas perdem eficácia ao se tentar manipular e controlar os desejos, os valores das pessoas e principalmente as necessidades pautadas na realidade $(P 4)$.

Os modelos de promoção e prevenção à saúde se configuram mais como produtores de procedimentos, sem assumir compromissos com os usuários e suas necessidades ${ }^{29}$.

A reconciliação das práticas assistenciais e a vida desse ser que essa categoria busca contemplar, almejando construir um cuidado mais cuidado (P1).

A construção de espaços coletivos, o diálogo e a tomada de decisão no cotidiano são fundamentais, pois sem eles ocorre uma paralisia do sistema e uma sobrecarga de questões e decisões desnecessárias para outros espaços coletivos, considerando que o imprevisível é aliado constante em nossas vidas (P6).

Os procedimentos passam a ser a finalidade ultima do trabalho, e assim configura-se um modelo contraditório com a missão do próprio SUS, o cuidado. A ação de saúde centrada na lógica da produção de cuidado traduz-se no trabalho orientado aos problemas, necessidades e qualidade de vida do usuário ${ }^{30}$.

Na prática pedagógica, a categoria reconstrutiva se articula com a necessidade de mudança do paradigma dominante do ensino, e a inovação do processo ensino-aprendizagem é a chave para o alcance do cuidado desejado.

A inovação contribui para a ruptura com o paradigma dominante, fazendo avançar, em diferentes âmbitos, formas alternativas de trabalho que quebram a estrutura tradicional. Uma inovação, contudo, não se caracteriza simplesmente pelo uso de novos elementos tecnológicos no ensino. É preciso que 
ela represente novas formas de pensar o ensinar e o aprender, numa perspectiva emancipatória. Uma experiência inovadora é um processo situado num contexto histórico e social, que exige uma ruptura com procedimentos acadêmicos inspirados nos princípios positivistas da ciência moderna ${ }^{31}$.

\section{CONSIDERAÇÕES FINAIS}

Resgatando todas as contribuições e análise das dimensões e competências do cuidado descritas no fórum em estudo, pode-se afirmar que o enfoque central foi a abordagem do cuidar que extrapola o ato técnico (centrado em procedimentos e abordagem flexneriana), onde se destaca a ênfase em outras dimensões que devem orientar as práticas do cuidado à saúde em todos os seus níveis: a humanização, a integralidade, a eqüidade, a acessibilidade, o acolhimento (amparar, sustentar), o vinculo, a aliança, a responsabilização, a inter-relação, a interação, a confiança, o afeto, a dignidade, a espiritualidade, a solidariedade, o acolhimento, a alteridade, o carinho, a confiança, o respeito e a dignidade.

Vimos que "o como" relacionado com o sentido do cuidado se dá pelos pactos, compartilhamento de poderes, produção de conhecimento que considera a realidade, troca benéfica para com os parceiros, formando ativadores, estabelecendo parcerias, inclusive o estabelecimento de redes de informação, participação representativa da comunidade, criação de espaços democráticos e utilização do método da roda. Assim, a proposta de mudança da formação do ensino superior para uma assistência qualificada e comprometida com as necessidades dos usuários tem neste sentido o seu cerne principal.

Cuidar é muito mais que dar condições de bem-estar ao "paciente" num dado momento da assistência, mas também na espera da consulta, facilitar o acesso do usuário aos serviços necessários, garantir exames complementares e consultas especializadas, atender dentro da técnica correta, atender o indivíduo com respeito e de forma digna, se preocupar com o sofrimento do outro e se mobilizar para a busca de soluções, co-responsabilizar o outro pelo seu cuidado, garantir a continuidade do tratamento, utilizar a informação de forma que a comunicação seja um instrumento de ligação entre os atores envolvidos. Todos esses elementos podem ser pactuados com a comunidade de forma que ela diga o que incomoda, exteriorize seus conflitos, expresse sua opinião sobre as formas de mudança para melhorar o serviço e a relação com os profissionais, transformando-se em protagonista — sujeito ativo do processo.

Os cuidados trazem a marca da diversidade de saberes e até mesmo de interesses. Não há como propor um projeto para que o cuidar se realize de forma homogênea. É preciso estar alerta para os princípios norteadores e aspectos metodológicos coerentes com o tipo específico do cuidar. O fazer deve reunir a expressão das dimensões práticas e teóricas dos saberes e fazeres multidisciplinares, intencionalidades dirigidas às necessidades identificadas, que diferem de pessoa para pessoa, de grupo para grupo, de serviço para serviço e de equipe para equipe. Cuidado é ato político, prática social, e a diferença só é estabelecida se os sentidos do cuidado estiverem vinculados à questão da cidadania e responsabilidade social.

\section{REFERÊNCIAS}

1. Timoteo RPS, Liberalino FN. Reflexões a cerca do fazer pedagógico a partir de referências e diretrizes educacionais para a formação em enfermagem. Rev Bras Enferm 2003; 56(4): 358-60.

2. Okada ALP 2003. Desafio para EAD: como fazer emergir a colaboração e a cooperação em ambientes virtuais de aprendizagem?. In: Silva M, org. Educação online: teorias, práticas, legislação e formação corporativa. São Paulo: Loyola; 2003. p. 273-91.

3. Polak YNS, Reich STS. Abrindo trilhas, descortinando novos horizontes na educação a distância. Formação 2002; 2(4): 59-72.

4. Silva M. Sala de aula interativa. Rio de Janeiro: Quartet; 2000.

5. Ferrero YP. Grupos operativos y educación para la salud: experiencia en el hospital "A. Zatti", Viedma Argentina. Disponivel em < http:/ / www.monografias.com>. [Acesso em: 27 de junho de 2007].

6. Bardin L. Análise do conteúdo. Lisboa: Edições 70; 1977.

7. Ayres JRCM. Cuidado e reconstrução das práticas de saúde. Interface comum. Saúde educ 2004; 8(14): 73-91.

8. Gruber TR. Towards principles for the design of ontologies used for knowledge sharing. Int J Hum Comp Stud (IJHCS) 1995; 43 (5/6): 907-28.

9. Boff L. Saber cuidar. Petrópolis: Vozes; 1999.

10. Ayres JRCM. Cuidado: tecnologia ou sabedoria prática? Interface comum. Saúde educ 2000; 6:117-21.

11. Santos AM, Assis MMA. Da fragmentação à integralidade: construindo e (des) construindo a prática de saúde bucal no Programa de Saúde da Família (PSF) de Alagoinhas, BA. Cien Saude Colet 2006; 11(1): 53-61.

12. Oliveira ME, Felini RM, Zampieri MF, Martins CR. Um ensaio sobre a comunicação no cuidado de enfermagem utilizando os sentidos. Enfermería Global [online]. 2006 mayo [capturado em 27 jun. 2007]; (8). Disponível em: <http:/ / www. um. es/ojs/index.php/eglobal/issue/view/63 
13. Schraiber LB. Medicina tecnológica e prática profissional contemporânea: novos desafios, outros dilemas São Paulo; 1997. Doutorado [Tese] — Faculdade de Medicina, Universidade de São Paulo.

14. Pires MRGM. Politicidade do Cuidado e Avaliação em saúde: instrumentalizando o resgate da autonomia de sujeitos no âmbito de programas e políticas de saúde. Rev. bras. saúde matern. infant 2005; 5 (Supl 1): 71-81.

15. Merhy EE, Cecilio LCO. O singular processo de coordenação dos hospitais. Saúde debate 2003; 27(64): 110-22.

16. Foucault M. História da sexualidade 3: o cuidado de si. Rio de Janeiro: Graal;1985.

17. Foucault M. Hermeneutica del sujeto Madrid: La Piqueta; 1987

18. Pettengill MAM, Nunes CB, Barbosa MAM. Professor e aluno compartilhando da experiência de ensino-aprendizagem: a disciplina de enfermagem pediátrica da Universidade Federal de Mato Grosso do Sul. Rev Lat Am Enfermagem 2003;11(4): 453-60.

19. Mattos RA. Os sentidos da integralidade: algumas reflexões acerca de valores que merecem ser defendidos. In: Pinheiro R, Mattos RA, orgs. Os sentidos da integralidade na atenção e no cuidado à saúde. Rio de Janeiro: IMS/UERJ, Abrasco; 2000.p.139-64.

20. Acioli S. Os sentidos das práticas voltadas para a saúde e doença: maneiras de fazer de grupos da sociedade civil. In: Pinheiro R, Mattos RA, orgs. Os sentidos da integralidade na atenção e no cuidado à saúde. Rio de Janeiro: IMS/Uerj, Abrasco; 2001.p. 157-66.

21. Campos GWS. Um método para análise e co-gestão de coletivos. São Paulo: Hucitec; 2000.

22. Silva NEK. Limites do trabalho multiprofissional:estudo de caso dos centros de referência para DST /Aids. Rev Saude Publica 2002; 36(4):108-16.

23. Campos GWS. Subjetividade e administração de pessoal: considerações sobre modos de gerenciar trabalho em equipes de saúde. In: Merhy EE, Onocko R, orgs. Agir em saúde: um desafio para o público. São Paulo: Hucitec; 1997. p. 229-66.
24. Chassot A. (Re)Pensando ações docentes: sobre como professoras e professores podem transformar o seu fazer pedagógico. In: Moraes VRP, org. Melhoria do ensino e capacitação docente. Porto Alegre: Editora da Universidade; 1996. p.87-101.

25. Bordas MC. Apresentação. In: Moraes VRP, org. Melhoria do ensino e capacitação docente. Porto Alegre: Editora da Universidade; 1996.

26. Morin E. A cabeça bem-feita: repensar a reforma, reformar o pensamento. Rio de Janeiro: Bertrand Brasil; 2004.

27. Passadori R. A arte da comunicação interpessoal. Gestão Plus 1999; IV(11): 22- 23.

28. Ferreira MLSM. Avaliação no processo ensino-aprendizagem: uma experiência vivenciada. Rev. bras. educ. méd. 2003; 27(1): 12-9.

29. Franco TB, Bueno WS, Merhy EE. O acolhimento e os processos de trabalho em saúde: o caso de Betim, Minas Gerais e Brasil. Cad Saude Publica 1999;15(2):345-53.

30. Matumoto S, Fortuna CM, Mishina SM, Pereira MJB, Domingos NAM. Supervisão de equipes no Programa de Saúde da Família: reflexões a cerca da produção de cuidados. Interface comum. Saúde educ. 2005; 16(9): 9-24.

31. Cunha MI, Marsico HL, Borges FA, Tavares P. Inovações pedagógicas na formação inicial de professores. In: Fernandes CMB, Grillo M, orgs. Educação superior: travessias e atravessamentos. Canoas: Ed. ULBRA; 2001. p. 33-90.

\section{CONFLITOS DE INTERESSE}

Declarou não haver

\section{ENDEREÇO PARA CORRESPONDÊNCIA}

Maria de Lourdes da Silva Marques Ferreira

Faculdade de Medicina de Botucatu - Departamento de Enfermagem

Distrito de Rubião Júnior, $\mathrm{s} / \mathrm{n}$

Campus Universitário - Botucatu

Cep.18618-970 / SP

E-mail: malusa@fmb.unesp.br 